\title{
TimberTower wins the German timber construction prize
}

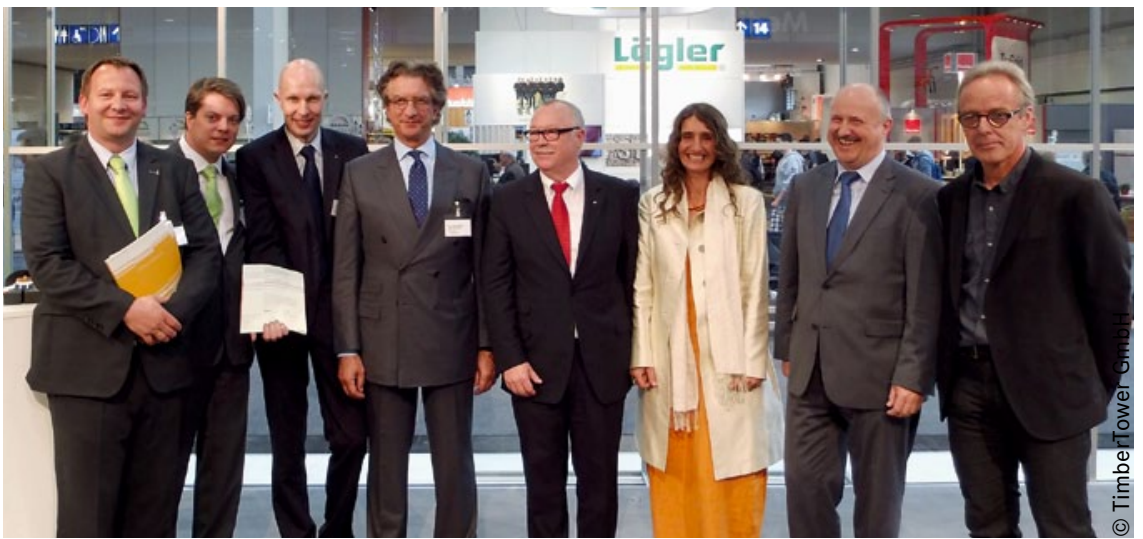

$\mathrm{D}$ uring this year's Ligna exhibition, the Central Association of the German Construction Industry (ZDB) awarded the German timber construction prize to TimberTower GmbH. The jury praised the 100-metre high wooden tower used for wind turbines, which is known under the brand name TimberTower and constructed using state-of-the-art adhesive systems, for being a unique structure and also for representing the competitiveness of wood as a construction material, in comparison with conventional materials. As managing director Holger Giebel explained: "We were awarded prizes before we built the tower, during the construction process and now that it is in operation. Wood is unbeatable. I would like to thank the jury for their decision and everyone who has made this
The award ceremony for the German timber construction prize: (from left) Gregor Prass, managing director of TimberTower, Holger Giebel, managing director of TimberTower, Ulf Cordes, managing director of Ing. Holzbau Cordes, Professor Edwin Kohl, partner in TimberTower, Ullrich Huth, Holzbau Deutschland (jury), Sabine Djahanschah, Deutsche Bundestiftung Umwelt (jury), representative of the German Federal Ministry of Transport, Building and Urban Development, Professor Hermann Kaufmann, architect (chairman of the jury)

and even higher towers possible." When it was still a start-up in 2008, TimberTower GmbH won the climate protection prize. In 2009 it was awarded the Schweighofer prize and in 2013 it was recognised as the "success of the decade". TimberTower has been working on a 140-metre high wooden tower since 2012 and this is only possible because of the use of adhesives.

\section{8th Munich Adhesives and Finishing Symposium}

The 38th Munich Adhesives and Finishing Symposium will take place from 28 to 30 October 2013. It is aimed at product and machinery manufacturers, formulators, users and end consumers of the adhesives, printing and converting industry. The event highlights the latest development trends and presents new raw materials, formulations and applications.

The organisers Stephan Hinterwaldner have once again succeeded in putting together an interesting programme.

The highlights include presentations on specialist tapes with UV-acrylic hot melts and on "the causal relationship between pneumatic hand applicators and hot melt adhesives". Other subjects under discussion are additives and what they can achieve in hot melts, the sus- tainable product design of adhesives and new bio-based solutions for tailoring reactive polyurethane hot melt properties. Speakers will also be considering topics such as biopolymeric coatings on fibrebased packaging, carbon nano-tubes as manageable components in adhesives and the dependence of die cutting behaviour on tackifier resins.

Further presentations include future-proof bonding with PO hot melts and a novel approach to extending the possibilities of hot melt acrylic formulation. The planned plenary lecture on the subject of hot melts, the most successful bonding technology of the last 50 years, will undoubtedly attract a great deal of interest from participants.

For more information: info@HiwaConsul.de, www.mkvs.de 